\title{
Compact Wideband Printed Slot Antenna with a Star Shaped Parasitic Patch
}

\author{
Neha Gandotra \\ PhD Scholar, IFTM University, \\ Moradabad
}

\author{
Prachi Gupta \\ M.Tech Student, \\ Dehradun institute of technology
}

\begin{abstract}
In this letter, a technique for enhancement of bandwidth along with gain is proposed here. This article deals with design, modeling and simulation of slotted antenna. A star shaped parasitic patch is introduced in the centre of antenna to improve the gain along with the bandwidth by exciting additional resonances. For enhancing bandwidth, a slotted approach is used in ground of antenna along with rotation in patch and a simple $50 \Omega$ microstrip line fed is used to excite the slot in the antenna. Simulated results shows that a good amount of bandwidth (approx. $2.89 \mathrm{GHz}$ ) and gain (approx. $8.05 \mathrm{~dB}$ ) is achieved ranging from 2.37 to $4.55 \mathrm{GHz}$ using Ansoft HFSS software. The proposed antenna shows its application in WIMAX and WLAN bands along with comparative analysis between parasitic patch and without parasitic patch at the last.
\end{abstract}

\section{Keywords}

High Frequency Structure Simulator, MSA (Microstrip Patch Antenna), Parasitic Patch, Wide-Slot Antenna

\section{INTRODUCTION}

Printed slot antennas are widely used in variety of wide band applications and are getting more and more popular because of advantages of wide frequency bandwidth, low profile, light weight, ease of fabrication and integration with other devices. The two orthogonal modes in wide slot antennas are merged to create a wide impedance bandwidth [1]. By coupling between the feeding structure and slot, wide bandwidth is obtained. A printed wide slot antenna with fork like tuning stub fed by micro strip line provides good bandwidth [2]. The impedance bandwidth has been broadened rapidly from 58\% to $130 \%$ by using combination of different feed shapes and wide slots have been reported [3-5]. In literature [6] significant bandwidth is achieved just by rotating slot around centre of square slot. By etching a wide slot as fractal shapes can also improve bandwidth in proposed slot antenna [7].Various wide slot antennas having different slot shapes including rectangle, ellipse, L-shape, circle and square have been reported here[8-12].

In slot antenna design technology,, a common and effective way to achieve wide impedance bandwidth is to make certain number of adjacent modes overlap with each other. Use of parasitic star patch in the centre of rotated slot is intended for gain maximization as well as bandwidth. Analysis of rotation of parasitic patch is also produced which satisfies that the gain and bandwidth are maximized at an angle of 45 degree. By use of star parasitic patch in slot center, it is shown that $\mathrm{f1}$ (lower resonant frequency) is decreased and f2 (higher resonant frequency) is increased thus broad band characteristic is obtained. Then, by use of the parasitic patch printed symmetrically to the feeding line, the bi-directional radiation feature is changed into unidirectional with enhanced gain. UWB applications helped in obtaining multi-standard functionality and higher data rate as compared to any other narrow band application(s).

From the simulated results, the achieved impedance bandwidth (determined from -10-dB reflection coefficient) of the proposed antenna can operate from 2.37 to $4.55 \mathrm{GHz}$ covering the WLAN bands and WiMAX bands. By optimization the dimensions of ground reduces from $70 \mathrm{~mm}$ to $37 \mathrm{~mm}$ for bandwidth and gain maximization along with reduced area constraint i.e. about $72 \%$. The proposed antenna is simulated using HFSS which is based on FEM.

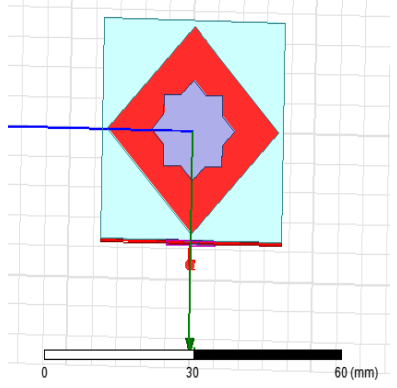

Fig 1: design of slot antenna with parasitic patch

\section{ANTENNA GEOMETRY AND DESIGN}

Proposed design of micro strip parasitic patch antenna is shown in the figure.1.Yagi-Uda antenna offers a concept for improving antenna gain. In this approach parasitic patches are printed on suitable position in the antenna and the effects on the gain are investigated. The proposed antenna has a simple geometry, consist of square slot and star shaped parasitic patch with some angle of rotation .The printed square slot antenna's dimensions are $24.7 \times 24.7 \mathrm{~mm}^{2}$ which is printed on FR-4 substrate having thickness $1.8 \mathrm{~mm}$ and relative permittivity 4.4. The reason for choosing FR-4 substrate is its low cost. The ground dimensions are taken as $37 \times 37 \mathrm{~mm}^{2}$. The square slot is fed by $50 \mathrm{ohm}$ micro strip line which is printed on other side of substrate. The feed line shown in figure is having the dimensions of $3 \times 31.5 \mathrm{~mm}^{2}$. For bandwidth maximization the square slot rotation is performed at an angle of $45^{\circ}$ and star shaped parasitic patch is applied having the dimensions of $12 \times 12 \mathrm{~mm}^{2}$ to enlarge the resonant frequency interval between the first and the second modes.

\section{RESULT ANALYSIS}

The simulated results are shown in figures below using Ansoft HFSS software

\subsection{Return loss of proposed antenna}

Return loss is a measure of how well antenna matching is done. The return loss of proposed antenna at two resonant 
frequencies $(2.37 \& 4.55)$ is $-16.3 \mathrm{~dB} \&-24.3 \mathrm{~dB}$ as shown in figure 2.

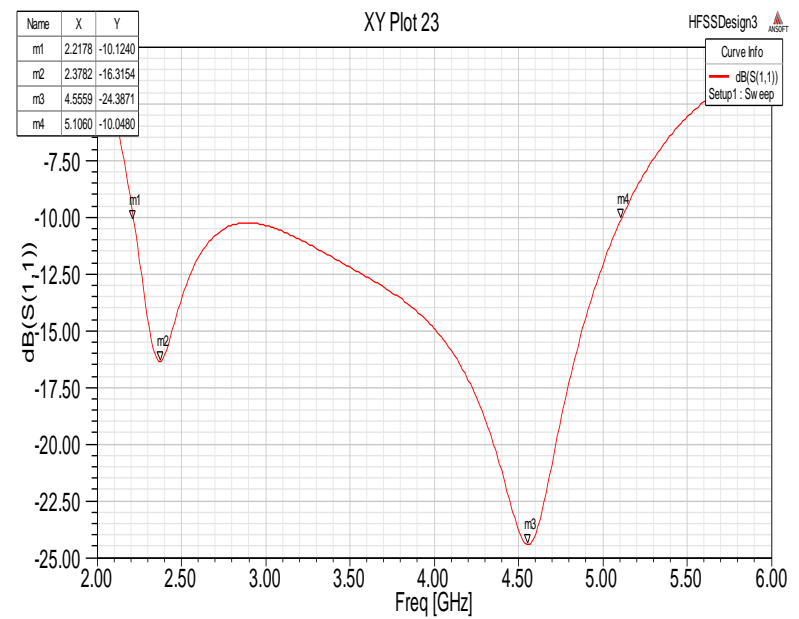

Fig 2: Return loss

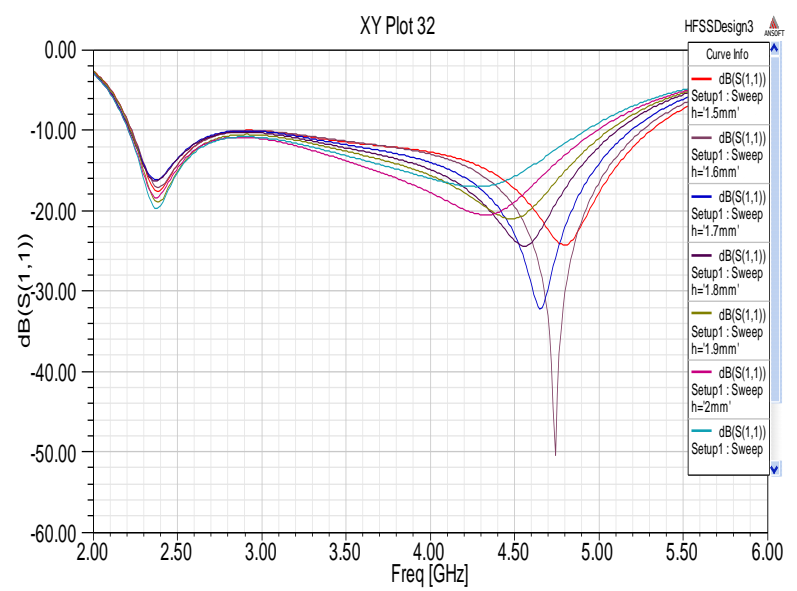

Fig3: Return loss with different heights of substrate

\subsection{Bandwidth of Proposed antenna:}

Bandwidth describes the range of frequencies over which the antenna can properly radiate or receive energy. We can see that on changing the values of ground plane have effect on the bandwidth of proposed antenna. Substrate thickness is another important parameter in achieving wide band performance as shown in figure 3. By applying parametric, as the value of substrate height increases from $1.5 \mathrm{~mm}$ to $2.1 \mathrm{~mm}$, the bandwidth increases and achieves better results at $1.8 \mathrm{~mm}$. The impedance bandwidth obtained from the simulation results ranging from $5.1-2.21 \mathrm{GHz}$ at $-10 \mathrm{~dB}$ return loss. That is 2.89 $\mathrm{GHz}$ bandwidth is achieved as shown in above figure.

\subsection{VSWR of proposed antenna:}

The VSWR of proposed antenna lies in the range between 1 and 2 that is acceptable and is shown in figure. 4

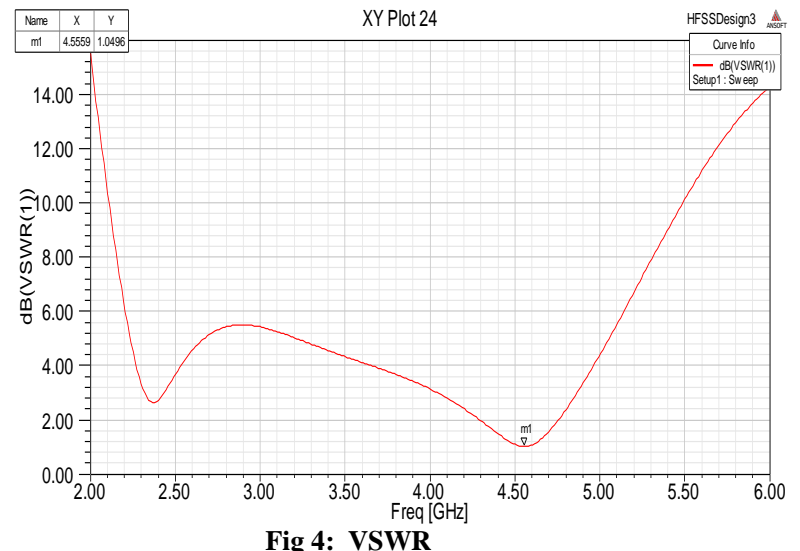

\subsection{Gain of proposed antenna}

Gain is defined as the ability of antenna to concentrate energy in a narrow angular region( a directive beam).The 3D polar plot of gain are measured with the help of an infinite sphere setup in far field.

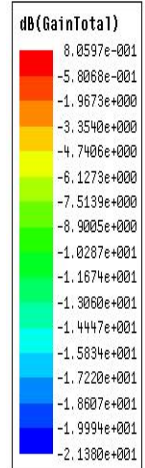

Fig 5: gain

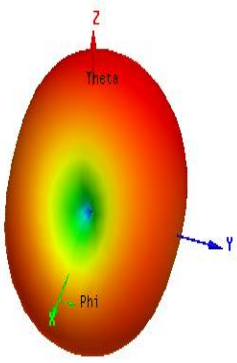

The gain so obtained at angle 45 degree is maximum i.e. 8.05 $\mathrm{dB}$ as shown in figure 5 .

\section{COMPARATIVE ANALYSIS}

The comparison has been made between without parasitic patch and rotation and with parasitic patch along with rotation on the basis of return loss, bandwidth and gain. The reference antenna i.e. without parasitic patch and rotation has ground dimensions of $70 \times 70 \mathrm{~mm}^{2}$ and with parasitic patch has dimensions of $37 \times 37 \mathrm{~mm}^{2}$ thus area is reduced up to $72 \%$. The return loss of reference antenna is $-17.44 \mathrm{~dB}$ at resonant frequency of $3.58 \mathrm{GHz}$ is shown in fig 7 which shows very good impedance matching. The bandwidth so obtained is about $0.6 \mathrm{GHz}(3.97-3.37 \mathrm{GHz})$.The gain so obtained in this case is about $6.09 \mathrm{~dB}$ as shown in figure 8 . The design of reference antenna without parasitic patch $\mathrm{n}$ rotation is shown in figure 6. 


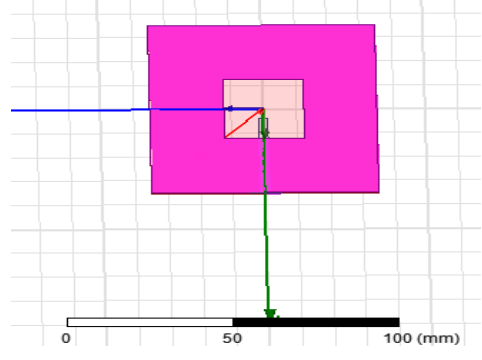

Fig 6: without parasitic patch

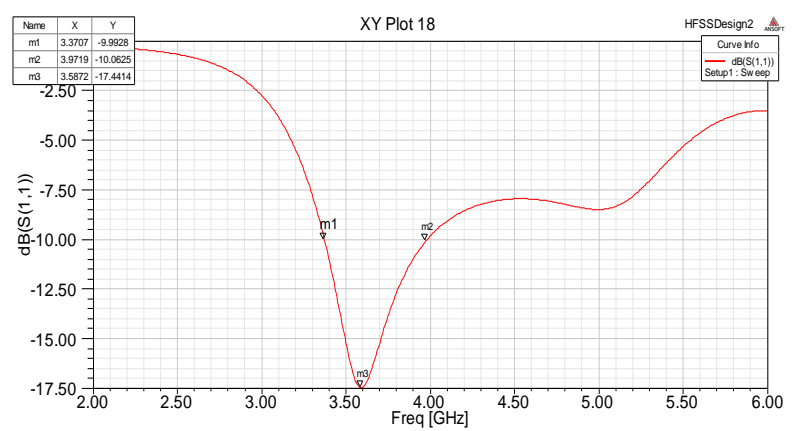

Fig 7: return loss of reference antenna

The proposed antenna i.e. with parasitic patch and proper rotation at angle $45^{\circ}$ has ground dimensions of $37 \times 37 \mathrm{~mm}^{2}$.The variations are in the dimensions of ground and all other parameters are same as given in design methodology and thickness of substrate is increased to $1.8 \mathrm{~mm}$ to optimize results. The return loss of proposed antenna is about $-24.3 \mathrm{~dB}$ and the bandwidth so obtained is about $2.89 \mathrm{GHz}$ which is about 4.8 times better than reference antenna. The results of gain is about $8.05 \mathrm{~dB}$ which is also better than reference antenna only by rotation of parasitic patch.
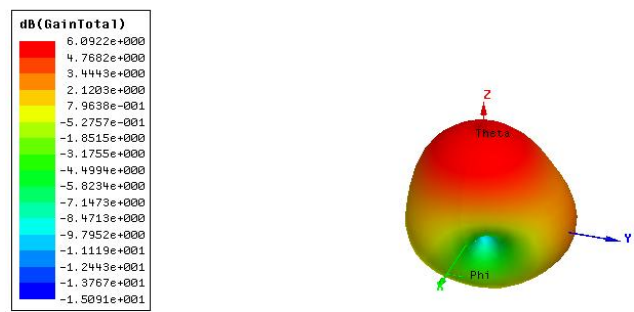

Fig 8: gain of reference antenna

The graphical representation of comparative analysis is shown in figure 9 which indicates that proposed antenna's performance is much better than reference antenna

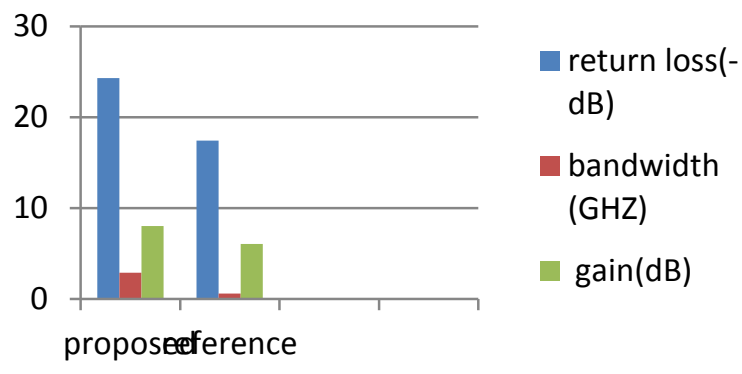

Fig 9: comparative analysis

\section{CONCLUSION}

A printed slot antenna with star shaped parasitic patch has been implemented and studied in this work. The bandwidth of proposed slot antenna by introducing a star parasitic patch into rotated square slot can significantly increased up to 2.89 $\mathrm{GHz}$ which is about 4.8 times wider than the reference antenna. On rotating the parasitic patch at different angles, the gain is enhanced up to $8.05 \mathrm{~dB}$ thus improves the performance of antenna. The proposed antenna is applicable for WIMAX and WLAN bands. Furthermore we are trying to do miniaturization of this antenna so that it will use comparatively lesser area for implementation.

\section{REFERENCES}

[1] M. Kahrizi, T. K. Sarkar and Z. A. Maricevic, "Analysis of a wide radiating slot in the groundplane of a microstrip line,'IEEE Trans. Antennas Propag., vol. 41, no. 1, pp. 29-37, Jan. 1993..

[2] J. Y. Sze and K. L. Wong, "Bandwidth enhancement of a microstrip line-fed printed wide-slot antenna," IEEE Trans. Antennas Propag., vol. 49, no. 7, pp. 1020-1024, Jul. 2001.

[3] W.L Stutz man and G.A Thiele. "Antenna Theory and Design”. John Wiley Sons, Inc,1998.

[4] Girish Kumar and K.P Ray," Broadband Microstrip Antennas", Artech House, 2003, pp 3-5.

[5] S.-W. Qu, C. Ruan, and B.-Z. Wang, "Bandwidth enhancement of wide slot antenna fed by CPW and microstrip line,'IEEE Antennas Wireless Propag. Lett., vol. 5, pp. 15-17, 2006.

[6] J.-Y. Jan and J.-W. Su, "Bandwidth enhancement of a printed wide-slot antenna with a rotated slot,"IEEE Trans. Antennas Propag. vol. 53, no. 6, pp. 2111-2114, Jun. 2005.

[7] W.-L.Chen, G.-M.Wang, andC.X. Zhang, "Bandwidth enhancement of a microstrip-line-fed printed wide-slot antenna with a fractal-shaped slot,"IEEE Trans. Antennas Propag., vol. 57, no. 7, pp. 2176-2179,Jul. 2009.

[8] W. S. Chen, "A novel broadband design of a printed rectangular slot antenna for wireless communications, ”Microw. J., vol. 49, no. 1, pp.122-130, Jul. 2006

[9] P. Li, J. Liang, and X. Chen, "Study of printed elliptical/circular slot antennas for ultra wideband applications, "IEEE Trans. Antennas Propag., vol. 54, no. 6, pp. 1670-1675, Jun. 2006.

[10] T. Dissanayake and K. P. Esselle, "UWB performance of compact L-shaped wide slot antennas,"IEEE Trans. Antennas Propag., vol. 56, no. 4, pp. 1183-1187, Apr. 2008

[11] S.-W. Qu, J.-L. Li, J.-X. Chen, and Q. Xue, "Ultra wideband strip loaded circular slot antenna with improved radiation patterns," IEEE Trans. Antennas Propag., vol. 55, no. 11, pp. 3348-3353, Nov.2007

[12] Prachi Gupta and Brajlata Chauhan, "Performance analysis of bandwidth and gain improvement of printed wide slot antenna using parasitic patch," Scientific research and essays,vol.9 no.11,pp. 661-667, 15 August, 2014 